\title{
A case report on decidual cast
}

\author{
Shikha Verma*, Ritu Goyal \\ Department of Obstetrics and Gynecology, DDU Hospital, Hari Nagar, New Delhi, India
}

Received: 19 September 2016

Accepted: 15 October 2016

\author{
*Correspondence: \\ Dr. Shikha Verma, \\ E-mail: shikhav48@yahoo.com
}

Copyright: $\odot$ the author(s), publisher and licensee Medip Academy. This is an open-access article distributed under the terms of the Creative Commons Attribution Non-Commercial License, which permits unrestricted non-commercial use, distribution, and reproduction in any medium, provided the original work is properly cited.

\begin{abstract}
The mucous membrane lining of uterus is known as decidua once it is implanted with a fertilized egg. A decidual cast forms under the influence of hormones while preparing uterus for implantation and it can shed by taking the shape of uterus. It has well known association with ectopic pregnancy. Also it can occur with incomplete abortion as mentioned in this case report. Other conditions are use of progesterone, standard dose of oral contraceptive pills. Our patient 25 year unbooked gravida 3 parity 2 with 12 week period of gestation presented to emergency department with incomplete abortion with excessive bleeding and anaemia. She was shifted for surgical evacuation in which she passed decidual cast, a very rare finding. The histopathology report suggest retained product of conception with chorionic villi.
\end{abstract}

Keywords: Abortion, Anaemia, Decidual cast

\section{INTRODUCTION}

Decidua is endometrium that is hormonally prepared for pregnancy. Decidual cast is the entire sloughed endometrium that takes the form of the endometrial cavity. It may be associated with ectopic pregnancy, incomplete abortion, non-pregnant state with use of progesterone, DMPA, rarely with oral contraceptive pills. The theory of hyper-progesteronism has been hypothesized and cases have been observed of decidual cast expulsion following progesterone. ${ }^{1}$ Other theories proposed by Greenblatt ${ }^{2}$ include an overall increase in the secretion of progesterone and estrogen, subsequent thickening of the endometrium and resultant in complete desegregation with expulsion of tissue; excessive development of the spiral arteries, with subsequent vasodilatation followed by vasoconstriction and then shedding of this overdeveloped endometrium. Our case report is based on expulsion of decidual cast in pregnant women associated with incomplete abortion.

\section{CASE REPORT}

Our patient was 25 year old women gravida 3 parity 2 with period of gestation 12 week presented to emergency department with complain of excessive bleeding per vaginum and severe pain abdomen. Patient was an unbooked case with no ultrasound done before with urine pregnancy test positive. She presented with features of incomplete abortion and severe anaemia. Her vitals were pulse rate 98/min, blood pressure-80/60mm $\mathrm{Hg}$. Patient was stabilised with 2 wide bore I.V line, crystalloid infusion, moist oxygen inhalation, all investigation sent and blood was arranged. She per vaginal finding was: os open, uterus 10 week size, with bleeding per vaginum. Patient was prepared and shifted to emergency OT for surgical evacuation. Intraoperative finding was patient expelled some decidual cast along with some retained products of conception and check curettage was done. Sample was sent for histopatholocal examination (Figure 1). Postoperatively patient was given one unit blood, antibiotics were given and USG was done which was normal. 


\section{Histopathology report}

Macroscopy: Cast of uterine cavity $3 \times 4 \times 1 \mathrm{~cm}$.

Microscopy: Partially necrotic endometrium showing marked decidua like change of the stroma with evidence of retained products of conception with chorionic villi.

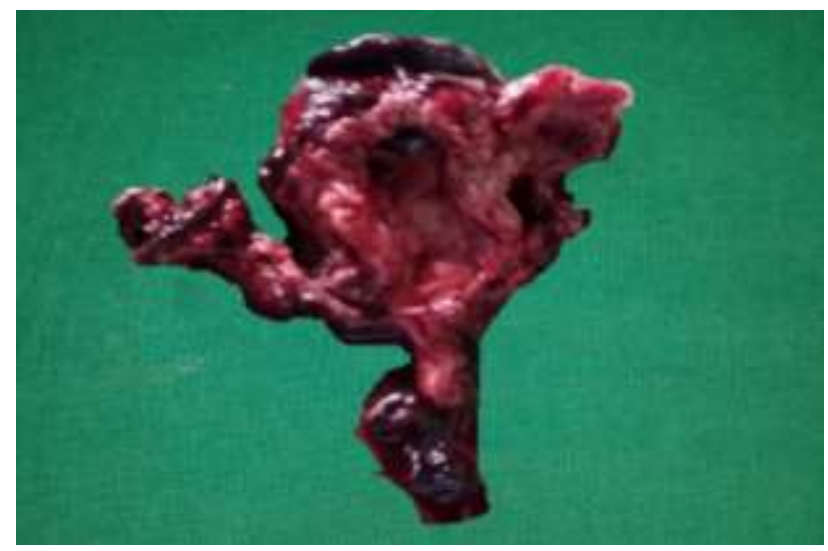

Figure 1: Decidual cast expelled with abortion at 12 weeks.

\section{DISCUSSION}

The lining of the pregnant uterus, other than the area taken up by the placenta, is called the decidua. The appearance of the normal lining of the uterus, by the effect of progesterone, becomes decasualised. When an area of decidua is shed, it is called a decidual cast because it frequently comes out in the shape of the uterine cavity. Decidual casts have a well know association with ectopic pregnancies. ${ }^{3}$ An ultrasonography an ectopic pregnancy with a decidual cast is often mistaken for an intrauterine pregnancy. ${ }^{4}$ Recent reports have described the sonographic appearance of the uterine decidua simulating an Intrauterine gestational sac in patients with ectopic pregnancy. ${ }^{5-7}$ Morgan G. Dunne described a case in which the shedding decidual cast simulated not only an intrauterine gestational sac but also a fetal pole within the sac. ${ }^{8}$ Membranous dysmenorrhoea is rare and causes intense cramping pain as a result of the passage of intact endometrial cast through an undilated cervix. ${ }^{9,10}$ A rare case report of passage of decidual cast tissue in a 16-yearold girl presented to our department with severe abdominal pain and vaginal bleeding on intake of Microgynon 30 micrograms (combined oral contraceptive pill, standard dosage) to take back to back for heavy painful periods. ${ }^{11}$ Another case series conducted on six paediatric patients on Depo Medroxy progesterone acetate, transdermal contraceptive patch and oral contraceptive, showing association of membranous dysmenorrhea with expulsion of Decidual cast. ${ }^{12}$
Recently there has been a suggestion that membranous dysmenorrhea is correlated with DMPA. ${ }^{13}$

\section{CONCLUSION}

Decidual cast is a rare case which is result of hyperprogertonosm that is the effect of progesterone on uterine endometrium. It causes thickening and decidualisation of endometrium which may expelled in form of decidual cast. It has association with intrauterine pregnancy, ectopic pregnancy and hormonal pill intake

\section{ACKNOWLEDGEMENTS}

I believe it is of utmost importance to express sense of gratitude to my husband Dr. Sujit Kumar who guided me in this work.

\section{Funding: No funding sources \\ Conflict of interest: None declared \\ Ethical approval: Not required}

\section{REFERENCES}

1. Omar and Smith: Membranous Dysmenorrhea the Scientific World Journal. 2007;7:1900-3.

2. Greenblatt RB, Hammond MD, Clark SL. Membranous dysmenorrhea: Studies in etiology and treatment. Am J Obstet Gynecol. 1954;68:835-44.

3. Maxwell JP. On uterine casts. International Journal of Obstetrics and Gynaecology. 1929;36:544.

4. Bradley WG, Fiskie CE, Filly RA. The double sac sign in early intrauterine pregnancy: Use in exclusion of ectopic pregnancy. Radiology. 1982;143:223-6.

5. Mueller CE. Intrauterine pseudo gestational sac in ectopic pregnancy. JCU. 1979;7:133-6.

6. Marks WM, Filly RA, Callen PW, Laing EC. The decidual cast of ectopic pregnancy: A confusing ultrasonographic appearance. Radiology. 1979;133:4514.

7. Spirt BA, O'Hara KA, Gordon L. Pseudo gestational sac in ectopic pregnancy: sonographic and pathologic correlation. JCU. 1981;9:338-40.

8. Dunne MG. Shed Decidual Cast stimulating an Intrauterine fetus. AJR. 1982;139:591-3.

9. Mayo JL. A healthy Menstrual Cycle. Clinical Nutrition Insights. 1997;5:9.

10. Rabinerson D, Kaplan B, Fisch B, Braslavski D, Neri A. Membranous dysmenorrhea: the forgotten entity. Obstet Gynecol. 1995 May;85(5):891-2.

11. Pingili R, Jackson W. Decidual Cast. The Internet Journal of Gynecology and Obstetrics. 2007;9(1).

12. Omar, Smith. Membranous Dysmenorrhea The Scientific World Journal. 2007;7:1900-3.

13. Scott S, Parrish A, Schlaff W, Stevens-Simons C. Decidual Casts Associated with DEPO Medroxyprogesterone Acetate Treatment in Adolescents. J Pediatr Adol Gynecol. 2005;18:217-8.

Cite this article as: Verma S, Goyal R. A case report on decidual cast. Int J Reprod Contracept Obstet Gynecol 2016;5:4478-9. 